\title{
Análise do impacto da adequação nos processos operacionais de tecnologia da informação às exigências da lei Sarbanes-Oxley em empresa do ramo financeiro
}

\author{
Analysis of the impact of adequacy on operational information technology processes to the \\ requirements of the Sarbanes-Oxley act in a financial company \\ Análisis del impacto de la adecuación de los procesos de tecnología de la información operativa a \\ los requisitos de la ley Sarbanes-Oxley en una empresa financiera
}

\author{
Adriano Arrivabene \\ ORCID: https://orcid.org/0000-0003-0110-4824 \\ Universidade de Guarulhos, Brasil \\ E-mail: arrivabenea@gmail.com \\ Renato José Sassi \\ ORCID: https://orcid.org/0000-0001-5276-4895 \\ Universidade Nove de Julho, Brasil \\ E-mail: sassi@uni9.pro.br \\ Pamela Ferreira Alves Andrelo \\ ORCID: https://orcid.org/0000-0003-2252-1504 \\ Universidade Nove de Julho, Brasil \\ E-mail: pamelafaandrelo@gmail.com \\ Maria Luiza Almeida de Oliveira Moura \\ ORCID: https://orcid.org/0000-0002-2439-9648 \\ Universidade Nove de Julho, Brasil \\ E-mail: luizaleyd_@uni9.edu.br
}

\begin{abstract}
Resumo
$\mathrm{Na}$ década de noventa algumas empresas norte-americanas de capital aberto, fraudaram seus resultados financeiros, gerando imagem de estabilidade irreal. Essa situação abalou o grau de confiança dos investidores, criando a Lei Sarbanes-Oxley (SOX), que obrigou as empresas a adequarem seus processos, inclusive os de Tecnologia da Informação (TI) às regras dessa lei. $\mathrm{O}$ objetivo deste trabalho foi analisar o impacto causado aos processos operacionais de TI com sua adequação às exigências da Lei SOX em empresa do ramo financeiro. Este objetivo foi buscado pela análise sobre as informações obtidas, comparando as situações de vários processos operacionais de TI nos períodos Pré e Pós SOX. Adotou-se a metodologia de pesquisa descritiva e a exploratória. Junto ao levantamento bibliográfico, dados reais relatados por profissionais que participaram das atividades abordadas no trabalho foram coletados por meio da aplicação de entrevista não estruturada. O levantamento bibliográfico mostrou, que apesar de importante são poucas as obras que apresentam o impacto e a adequação da Lei SOX aos seus processos operacionais de TI. Boa parte delas estão relacionadas à gestão de processos, o que revela a importância deste trabalho. Os resultados mostraram a necessidade de se implantar os processos de controle SOX, como a criação de uma tabela de controle para monitorar os processamentos, mostraram também que ocorreram aumentos nos tempos dos processamentos das rotinas batch e processamentos das aplicações online em virtude do aumento de informações geradas e armazenadas. Concluiu-se que ocorreu impacto nos processos operacionais com suas adequações às exigências da SOX.

Palavras-chave: Lei Sarbanes-Oxley; SOX; Governança corporativa; Governança de tecnologia da informação; Ramo financeiro.

Abstract

In the nineties, some US publicly traded companies defrauded their financial results, generating an image of unreal stability. This situation affected the degree of investor confidence, creating the Sarbanes-Oxley Act (SOX), which forced companies to adapt their processes, including those of Information Technology (IT) to the rules of that law. The objective of this work was to analyze the impact caused to the IT operational processes with their adaptation to the requirements of the SOX in a company in the financial sector. This objective was sought by analyzing the information obtained, comparing the situations of various IT operational processes in the Pre and Post SOX periods. Descriptive and exploratory research methodology was adopted. Along with the bibliographic survey, real data reported by professionals who participated in the activities covered in the work were collected through the application of unstructured interviews. The bibliographic survey showed that, although important, there are few
\end{abstract}


works that present the impact and the adequacy of the SOX to their IT operational processes. Most of them are related to process management, which reveals the importance of this work. The results showed the need to implement SOX control processes, such as the creation of a control table to monitor the processing, also showed that there were increases in the processing times of the batch routines and processing of the online applications due to the increase in information generated and stored. It was concluded that there was an impact on the operational processes with their adaptation to the requirements of SOX.

Keywords: Sarbanes-Oxley Act; SOX; Corporate governance; Information technology governance; Financial branch.

\section{Resumen}

En la década de 1990, algunas empresas estadounidenses que cotizan en bolsa defraudaron sus resultados financieros, creando una imagen de estabilidad irreal. Esta situación afectó el grado de confianza de los inversores, creando la Ley Sarbanes-Oxley (SOX), que obligó a las empresas a adecuar sus procesos, incluidos los de Tecnologías de la Información (TI), a las normas de dicha ley. El objetivo de este trabajo fue analizar el impacto causado a los procesos operativos de TI con su adecuación a los requerimientos de SOX en una empresa del sector financiero. Este objetivo se persiguió mediante el análisis de la información obtenida, comparando las situaciones de los distintos procesos operativos de TI en los periodos Pre y Post SOX. Se adoptó una metodología de investigación descriptiva y exploratoria. Junto con el levantamiento bibliográfico, se recogieron datos reales reportados por los profesionales que participaron en las actividades contempladas en el trabajo, mediante la aplicación de entrevistas no estructuradas. El relevamiento bibliográfico mostró que, aunque importante, hay pocos estudios que presenten el impacto y la adecuación de SOX a sus procesos operativos de TI. La mayoría de ellos están relacionados con la gestión de procesos, lo que revela la importancia de este trabajo. Los resultados mostraron la necesidad de implementar procesos de control SOX, como la creación de una tabla de control para monitorear el procesamiento, también mostraron que hubo un aumento en los tiempos de procesamiento de las rutinas por lotes y procesamiento de las aplicaciones en línea debido al aumento de la información generada y almacenado. Se concluyó que hubo impacto en los procesos operativos con su adaptación a los requerimientos SOX.

Palabras clave: Ley Sarbanes-Oxley; SOX; Gobierno corporativo; Gobierno de tecnologías de la información; Rama financiera.

\section{Introdução}

O relacionamento entre investidor e empresa é mantido em uma linha extremamente tênue. Os investidores analisam o mercado e confiam nas informações que recebem das empresas onde mantém seus capitais investidos e, mediante os cenários recebidos, analisam e direcionam seus capitais.

No final da década de noventa, esse relacionamento sofreu um choque. Foram descobertas fraudes na divulgação das informações dos resultados financeiros de algumas empresas norte-americanas. Essa descoberta gerou um impacto negativo mundial, pois essas empresas comercializavam suas ações na New York Stock Exchange (NYSE) e National Association of Securities Dealers Automated Quotations (NASDAQ), e ainda, estavam relacionadas entre as melhores empresas para se trabalhar (Borgerth, 2007).

Empresas como a Enron (setor de energia), Worldcom (telecomunicações), Arthur Andersen (auditoria), entre outras, manipularam as informações dos seus resultados fiscais com o objetivo de passar uma imagem de estabilidade financeira ao mundo corporativo e aos seus investidores, porém, não refletiam a realidade. Com tal ação, seu objetivo foi de evitar o abalo negativo em sua imagem e, consequentemente, a evasão dos investimentos com o término do relacionamento com seus investidores (Swartz, 2003).

As fraudes originaram uma das maiores reformas financeiras da história norte-americana: em julho de 2002 foi sancionada a Lei Sarbanes Oxley (SOX) como um organismo regulador das empresas de auditoria garantindo a integridade das informações e a responsabilidade penal da alta administração sobre elas (Wintoki, 2007).

O objetivo atribuído à criação da Lei SOX foi de restabelecer a confiança do mercado nas empresas e estabelecer a adoção de padrões éticos no tratamento das informações financeiras e seu respectivo direcionamento aos investidores (Borgerth, 2007; Solms, 2006). 
Como um organismo regulador das empresas de auditoria, a lei foi criada para garantir a integridade das informações e a responsabilidade penal da alta administração sobre elas.

As adequações à Lei SOX facilitam a implementação de controles internos que suportam as estratégias e as decisões sobre os negócios, melhorando os resultados financeiros interferindo no sistema ERP (Enterprise Resource Planning) com a transparência dos processos (Purcinelli et al., 2019).

Os requerimentos da lei afetaram a forma como as empresas de capital aberto passaram a relatar suas operações financeiras, impondo a responsabilidade penal na alta administração (Hinde, 2004; Posthumusa \& Solms, 2005).

Baseada nesses valores, a Lei SOX gerou a necessidade de adequações nas empresas que pretendiam iniciar ou dar continuidade na comercialização de suas ações nas bolsas norte- americanas gerando diversos impactos (Jain, Jain \& Rezaee, 2010).

Segundo Tham e Madni (2014) as empresas devem buscar novas maneiras de melhorar suas comunicações internas, otimizar seus processos operacionais, atividades financeiras e contábeis e monitorar o desempenho de seus negócios para a conformidade com a Lei SOX.

Os impactos foram analisados por diversos trabalhos destacando-se: Parkinson e Bloom (2003), que analisaram o impacto da Lei SOX nas empresas americanas em 2003, ou seja, um ano depois de promulgada a lei; Gelatti, Meneghetti e Silva (2010), que avaliaram o impacto da Lei SOX nas empresas brasileiras em 2010, no nível de gestão; Zalewska (2014), que apresentou um estudo sobre os dez anos de aplicação e impacto da Lei SOX e Rezaee (2004), que apresentou um estudo sobre o impacto da Lei SOX na Governança Corporativa.

Segundo Karpoff (2019) "os efeitos da mudança de tecnologia e o aumento da riqueza social para fazer previsões estáticas comparativas sobre as forças de longo prazo que provavelmente afetarão a incidência de fraud". Ainda, segundo Karpoff (2019), "a pandemia de COVID-19 e a paralisação econômica resultante também interromperam as demandas relativas e o capital organizacional de maneiras que provavelmente aumentarão a incidência de fraude nos próximos dois anos".

Segundo Kaarst-Brown e Kelly (2005), a lei gerou um impacto também na Governança de Tecnologia da Informação (TI) das empresas, pelo fato de que as exigências de adequação à lei determinem a geração de registros, controles e autorizações para a manipulação de quaisquer processos em que sejam manipuladas informações financeiras.

Dessa forma, todos os processos pertencentes às rotinas dos sistemas de informações financeiros e que em algum momento poderiam causar alguma variação nos resultados financeiros das empresas, foram analisados e sofreram adequações.

O processamento das aplicações financeiras na área de TI também foi impactado, pois, o tempo de execução dos processamentos foi estendido, assim como houve aumento do volume de informações armazenadas (Bequai, 2003).

A ocorrência desse impacto na adequação à Lei SOX e acatadas pela Governança de Tecnologia da Informação (GTI), além de ser vista como uma exigência para as empresas que pretenderam dar continuidade à comercialização de suas ações nas bolsas norte-americanas serviu também como uma oportunidade para as empresas reverem seus processos e avaliações dos controles internos (Luo, 2005; Todeva, 2005; Gelatti et al., 2010; Windsor, 2009).

A GTI é fundamental para garantir que a tomada de decisões de TI esteja alinhada com a estratégia da organização, mas também para controlar o alinhamento da TI como um todo às necessidades do negócio (Juiz \& Toomey, 2015). Ocorre também que a GTI pode levar à destruição de valor por meio de oportunidades perdidas ou atraso de inovação e aumento da exposição aos riscos de TI (Turel et al., 2019).

Em 2008, a ISO (International Organization for Standardization) definiu uma norma específica para a GTI, sua 
versão atual é a ISO 38500: 2015 (ISO, 2015). Esta iniciativa apresenta um framework que inclui três tarefas distintas para o ITG (Juiz \& Palacios, 2020):

1) Avaliar o uso de TI;

2) Preparação e implementação de planos e políticas;

3) Monitorar a conformidade com as políticas e o desempenho em relação aos planos.

Com o atendimento das empresas às exigências da Lei SOX surgiu a necessidade de se analisar a situação de cada um dos processos de cada uma das rotinas de processamentos nos sistemas de informação, que lidavam com informações financeiras, das empresas (Agrawal, Johnson, Kiernan \& Leymann, 2006).

Com as novas regras exigidas pelas adequações à Lei SOX, o resultado final dos processos envolvidos sofreu um impacto com respeito à sua operacionalidade (Weill \& Ross, 2004).

Esse impacto gerou a necessidade de serem implantados controles e autorizações nos acessos, uma vez que as exigências da Lei SOX, abordam dois pontos fundamentais (Kaarst-Brown \& Kelly (2005): garantia de segurança para as informações e o registro de controles auditáveis.

Esta necessidade motivou a realização deste trabalho, que teve como objetivo analisar o impacto causado aos processos operacionais de Tecnologia da Informação com sua adequação às exigências da Lei SOX em empresa do ramo financeiro.

Vale destacar que o impacto em áreas operacionais ainda é pouco estudado, o que indica a importância do estudo realizado neste trabalho.

\section{Fundamentação Teórica}

\subsection{Governança Corporativa}

O Instituto Brasileiro de Governança Corporativa (IBGC, 2020) define Governança Corporativa como um sistema que dirige, monitora e incentiva as empresas, envolvendo os relacionamentos entre sócios, conselho de administração, diretoria, órgãos de fiscalização e controle e demais partes interessadas.

A literatura em Governança Corporativa recebe contribuições únicas da teoria institucional com seus insights com foco na natureza de arquiteturas de autoridade e controle (Menezes, 2018).

Segundo Labadessa et al. (2020), a Governança Corporativa é um instrumento de gestão e segurança para as empresas, pois fomenta a segurança dos atos de gestão, do risco jurídico corporativo e da relação da relação com os stakeholders.

A finalidade da Governança Corporativa é aumentar valor para a sociedade, facilitar seu acesso ao capital e aprimorar o desempenho da organização. Visa garantir a ética da organização na geração e proteção dos benefícios para todos os investidores, certificando assim a continuidade dos relacionamentos entre eles e as empresas (Tariq \& Abbas, 2013; Badele \& Fundeanu, 2014; Li, Chen \& French, 2012; Broni \& Velentzas, 2012; Lo, 2012.

Visa também garantir aos sócios a equidade, transparência, responsabilidade pelos resultados (accountability) da empresa e total cumprimento das leis do país (compliance) também tidas como definições para a Governança Corporativa (Crespí-Cladera \& Pascual-Fuster, 2014; Tan, 2014; Claessens \& Yurtoglu, 2013; Kim \& Lu, 2013).

Lynch e Veland (2018) propoem a Governança urgente, distinguindo a auditoria que gera segurança e confiabilidade nos processos e, ao mesmo tempo, gera um fator negativo, um dano social. Exemplificando: uma usina eficiente em sua produção, porém, nociva ao meio ambiente através da poluição gerada (Leveson, 2011). 
A Governança Corporativa busca, essencialmente, a perpetuação das organizações. Trata- se de práticas de gerenciamento avaliadas por uma abrangência bastante significativa de posições, que se estendem desde questões legais, como o direito dos investidores, questões financeiras que medem o retorno do investimento e a geração de valor, chegando até questões externas à organização, como questões ambientais (Andrade \& Rossetti, 2004).

Segundo o IBGC (2020), o objetivo da Governança Corporativa é desenvolver e difundir as boas práticas e seus princípios, garantindo assim que as equipes atuem em conformidade com as boas práticas da empresa.

Por meio das práticas de Governança Corporativa, as instituições financeiras, aprimoram a prestação de contas, focando em transparência e preservação de interesses das partes interessadas, práticas essas que podem influenciar nas decisões dos investidores. (Souza et al., 2019).

Sievinen et al. (2020) discutem os processos de Governança como uma capacidade de mudança institucionalizada na empresa e ainda, afirmam que as regras seguidas pelos proprietários constituem um motivo subjacente para o estabelecimento desses processos, utilizados no cumprimento das regras definidas.

Schmitt et al. (2016) descreve que a renovação estratégica em empresas com a Governança atuante, como "o processo que permite às organizações alterar sua dependência de trajetória, transformando sua intenção e capacidades estratégicas".

Com sua atividade voltada diretamente a governar e dependente de tecnologia para poder desempenhar seu papel, a Governança Corporativa possui uma importante aliada: a Governança de Tecnologia da Informação (GTI) (Arrivabene, Sassi \& Romero, 2011).

A GTI determina as políticas, regras e procedimentos voltados à estrutura e processos informatizados de maneira a assegurar a sustentação e garantir informações confiáveis às estratégias da organização (Lunardi, Becker \& Maçada, 2012).

Os procedimentos determinados pela Governança de TI são criados a partir de regras hierárquicas de acessos e controles, aplicados nos acessos e nas informações manipuladas pelos usuários através dos Sistemas de Informações (Chan, 2004).

A sequência de atividades desenvolvidas sobre as informações das empresas é chamada de processos e, na área de TI essa sequência é chamada de Processos de TI. Estes são regrados e determinados pela Governança de TI, para todos os processamentos das informações das empresas (Lunardi et al., 2012).

Paré et al. (2019) afirma que as atividades da área de TI são a aquisição, parametrização, desenvolvimento e implantação de software, bem como o gerenciamento e monitoramento de processos e projetos.

\subsection{Lei Sarbanes-Oxley}

A lei assinada em 30 de julho de 2002 se tornou conhecida mundialmente pela junção dos sobrenomes de seus criadores, os senadores norte-americanos Paul Spyros Sarbanes e Michael Garver Oxley.

A lei busca a eficiência das informações no mercado de capitais, uma vez que os investidores utilizam estas informações para direcionar suas atividades, facilitando assim a análise do risco que estarão assumindo e avaliando qual a sua chance de retorno (Borgerth, 2007).

Como um organismo regulador das empresas de auditoria, a lei foi criada para garantir a integridade das informações e a responsabilidade penal da alta administração sobre elas. Suas exigências afetaram a forma como as empresas de capital aberto passaram a relatar suas operações financeiras, impondo a responsabilidade penal na alta administração. A Lei SOX determina que sejam processados aqueles que busquem destruir, alterar, ou falsificar informação financeira e seus respectivos registros (Swartz, 2003).

Segundo Borgerth (2007), a Lei SOX determina a obrigatoriedade de práticas de controle e segurança nos sistemas de 
informações, aplicativos e redes, além de rígidos critérios na utilização de aplicações terceirizadas por empresas sob o âmbito da lei.

Dividida em onze capítulos e em diversas seções, a Lei SOX tem na Seção 404 a definição dos controles internos da empresa e os critérios que avaliam esses controles. Nessa seção são abordadas as exigências que direcionam as adequações nos processos das informações dos sistemas de informações nas empresas.

Segundo Andrade e Rossetti (2004) a Lei SOX fundamenta-se nos quatro valores da própria Governança Corporativa: Compliance: estar de acordo e fazer com que se cumpram os regulamentos impostos às atividades da instituição; Accountability : devida prestação de contas aos níveis hierárquicos superiores; Disclosure: exposição de riscos e benefícios a fim de esclarecer a transparência nas informações e Fairness: garantia do senso de justiça.

A fundamentação da Lei SOX em valores como Compliance e Accountability, remete às atividades por ela regradas como auditáveis, garantindo assim uma maior segurança e tranquilidade aos investidores e mercado (Defond \& Francis, 2005). As auditorias financeiras buscam a garantia de que a empresa possua processos formais de Governança e aplicando-os formalmente: estabelecimento, cumprimento e comunicação de metas, sob um constante monitoramento, assegurando-se assim a confiabilidade (Soh \& Martinov, 2011).

Com a geração desse cenário auditável, a Lei SOX teve por objetivo garantir a aplicação das políticas da Governança Corporativa nas empresas, diminuindo a probabilidade e coibindo a ocorrência da prática de fraudes e, com isso, restabelecer a confiança dos investidores e mercado, estabelecendo a adoção de padrões éticos no tratamento das informações financeiras das empresas (Borgerth, 2007).

Segundo Borgerth (2007), existem dois pontos fundamentais que devem ser observados, com respeito à aplicabilidade da Lei SOX na disponibilização das informações das empresas pela utilização dos sistemas de informações e aplicativos:

1 - Segurança: a aplicação do conteúdo da Lei SOX deve ocorrer entre toda a cadeia de comunicação da empresa (processos) e nos recursos concernentes aos sistemas de informações financeiras (Parkinson \& Bloom, 2003).

2 - Controle de registros: a lei baseia-se no registro das informações que possam ser utilizadas no rastreamento das atividades desenvolvidas na manipulação de informações financeiras.

Esses controles asseguram a garantia da integridade do fluxo das informações. A Lei SOX enfatiza estratégias de contingência, planos alternativos para eventuais casos de pane que assegurem a continuidade das atividades envolvidas, essa estratégia contingente exige uma redundância monitorada de tecnologia, recursos e aplicativos de backup.

\section{Materiais e Métodos}

Adotou-se a metodologia de pesquisa descritiva e a de pesquisa exploratória. A pesquisa descritiva tem como objetivo a descrição das características de determinada população ou fenômeno ou, então, o estabelecimento de relações entre variáveis, uma de suas características mais significativas está na utilização de técnicas padronizadas de coleta de dados como a observação sistemática (Gil, 2002).

A Pesquisa Exploratória tem como objetivo proporcionar maior familiaridade com o problema, com vistas a torná-lo mais explícito ou a constituir hipóteses. Pode-se dizer que estas pesquisas têm como objetivo principal o aprimoramento de ideias ou a descoberta de intuições.

Na maioria dos casos, essas pesquisas envolvem: (a) levantamento bibliográfico; (b) entrevistas com pessoas que tiveram experiências práticas com o problema pesquisado; e (c) análise de exemplos que "estimulem a compreensão". Embora o 
planejamento da pesquisa exploratória seja bastante flexível, na maioria dos casos assume a forma de pesquisa bibliográfica ou de estudo de caso (Gil, 2002).

O levantamento bibliográfico foi realizado em consultas a fontes bibliográficas e de referencial teórico: artigos, livros, teses, dissertações e websites com conteúdo sobre Lei Sarbanes-Oxley, Governança Corporativa, Governança de Tecnologia da Informação e aplicação da Lei SOX no ramo financeiro.

Junto ao levantamento bibliográfico, dados reais relatados por dois analistas da área de produção de TI, que participaram das atividades abordadas no trabalho foram coletados a partir de fontes baseadas em relatos, documentos ou observações.

Um analista de produção da área de TI tem um perfil técnico, operacional, lida com informações das rotinas, alocação de espaço em disco e demais mídias. Uma de suas principais funções é garantir que os processamentos sejam executados completamente e dentro da "janela de produção", tempo de processamento onde ocorrem os processamentos batch e também acionar os analistas responsáveis em caso de cancelamentos.

Para tanto, aplicou-se a entrevista não estruturada. A entrevista não estruturada, caracteriza-se pela liberdade dada ao entrevistador. Nesse modelo, o mais indicado é que se estabeleça alguns pontos de interesse, os quais serão abordados ao longo da entrevista de emprego como: experiência técnica; experiência com liderança de equipes; formação acadêmica e interesses pessoais (Gil, 2002).

Ao longo da entrevista, o recrutador poderá se aprofundar em cada um desses pontos, da forma como achar mais conveniente. Mas é crucial fazer sempre perguntas abertas, ou seja, aquelas que não podem ser simplesmente respondidas com um "sim" ou "não" (Gil, 2002).

\subsection{Levantamento bibliográfico}

Apresenta-se na Tabela 1, as principais obras relacionadas ao tema deste trabalho oriundas do levantamento bibliográfico realizado. Destaca-se que nesta relação não se abordou o impacto em processos operacionais de TI em decorrência da adequação às exigências da Lei SOX, o que revela a importância do trabalho para a área em questão.

Tabela 1: Levantamento Bibliográfico.

\begin{tabular}{|c|c|c|c|}
\hline Autor(es) & Ano & Título & Principais considerações \\
\hline $\begin{array}{c}\text { Agrawal, R., Johnson, } \\
\text { C., Kiernan, J., \& } \\
\text { Leymann, F. (2006) }\end{array}$ & 2006 & $\begin{array}{c}\text { Taming Compliance with } \\
\text { Sarbanes-Oxley Internal } \\
\text { Controls Using Database } \\
\text { Technology }\end{array}$ & $\begin{array}{l}\text { Os autores concluíram que a tecnologia de banco de dados pode } \\
\text { desempenhar um papel importante no auxílio ao cumprimento } \\
\text { das disposições de controle interno da lei. Os principais } \\
\text { componentes da solução proposta incluem: (i) modelagem de } \\
\text { fluxos de trabalho necessários, (ii) aplicação ativa de atividades } \\
\text { de controle, (iii) auditoria de fluxos de trabalho reais para } \\
\text { verificar a conformidade com controles internos e (iv) OLAP } \\
\text { orientado por descoberta para identificar irregularidades em } \\
\text { dados financeiros. São ilustrados como os recursos da solução } \\
\text { proposta atendem aos requisitos da Lei SOX, usando vários } \\
\text { cenários da vida real. }\end{array}$ \\
\hline
\end{tabular}




\begin{tabular}{|c|c|c|c|}
\hline $\begin{array}{l}\text { Arrivabene, A., Sassi, } \\
\text { R. J., \& Romero, M. } \\
\text { (2011) }\end{array}$ & 2011 & $\begin{array}{l}\text { Corporate sustainability with } \\
\text { security to investors: } \\
\text { Analyses of Business } \\
\text { Intelligence governance } \\
\text { following the requirements } \\
\text { of Sarbanes-Oxley Law }\end{array}$ & $\begin{array}{l}\text { Os autores examinaram a governança de Business Intelligence e } \\
\text { como atender aos requisitos da Lei SOX. Concluíram que o } \\
\text { cumprimento da legislação gera mudanças nos processos, } \\
\text { criando registros para controle e mapeamento das atividades, } \\
\text { podendo ser rastreados até o envolvimento direto dos gestores } \\
\text { envolvidos nessas atividades. }\end{array}$ \\
\hline Bequai, A. (2003) & 2003 & $\begin{array}{l}\text { Safeguards for IT Managers } \\
\text { and Staff under the Sarbanes } \\
\text { Oxley Act. }\end{array}$ & $\begin{array}{l}\text { O trabalho, por meio de pesquisa empírica, apresenta que } \\
\text { ocorreu uma mudança no paradigma da segurança da } \\
\text { informação, passando de uma ferramenta de gestão defensiva a } \\
\text { uma ferramenta de gestão de valor agregado. Quatro estudos de } \\
\text { caso na Suíça, Reino Unido e Alemanha em setores bancários, } \\
\text { de telecomunicações e de software forneceram validação teoria } \\
\text { empírica das funções internas e externas da segurança } \\
\text { organizacional. }\end{array}$ \\
\hline $\begin{array}{c}\text { Gelatti, C. B., } \\
\text { Meneghetti, D., \& } \\
\text { Silva, T. M. (2010) }\end{array}$ & 2010 & $\begin{array}{l}\text { Análise da adequação das } \\
\text { empresas brasileiras à Lei } \\
\text { Sarbanes-Oxley }\end{array}$ & $\begin{array}{l}\text { As autoras analisaram o processo e as vantagens de adequação } \\
\text { das empresas brasileiras às regras estabelecidas pela Lei SOX. O } \\
\text { estudo trata de uma pesquisa descritiva e exploratória com a } \\
\text { finalidade de apresentar essa legislação, tema pouco discutido } \\
\text { no Brasil, até então, apesar de todas as empresas brasileiras com } \\
\text { ações negociadas no mercado norte-americano já estarem } \\
\text { adequadas à Lei. Para a obtenção dos resultados, foi submetido } \\
\text { um questionário às empresas adequadas à SOX e, em seguida, as } \\
\text { respostas da pesquisa foram analisadas comparativamente. }\end{array}$ \\
\hline $\begin{array}{c}\text { Kaarst-Brown, M. L., } \\
\text { \& Kelly, S. (2005) }\end{array}$ & 2005 & $\begin{array}{l}\text { IT Governance and Sarbanes } \\
\text { Oxley: The Latest Sales } \\
\text { Pitch or Real Challenges for } \\
\text { the IT Function? }\end{array}$ & $\begin{array}{l}\text { Os autores chamaram a atenção sobre o impacto potencial da Lei } \\
\text { SOX para a governança de TI, os orçamentos de TI e os } \\
\text { relacionamentos com fornecedores e terceirizadores. As } \\
\text { descobertas têm implicações para a pesquisa, bem como lições } \\
\text { práticas aprendidas para empresas americanas e para } \\
\text { fornecedores de TI ou outras empresas que fazem negócios com } \\
\text { empresas americanas. }\end{array}$ \\
\hline Menezes, A. M. (2018) & 2018 & $\begin{array}{l}\text { A Influência da Lei } \\
\text { Sarbanes-Oxley (SOX) nas } \\
\text { Normas e Regras Nacionais } \\
\text { da Governança Corporativa } \\
\text { no Setor de } \\
\text { Telecomunicações do Brasil. }\end{array}$ & $\begin{array}{l}\text { O objetivo do trabalho foi compreender como se deu a } \\
\text { influência da Lei SOX no processo de elaboração das normas e } \\
\text { regras de Governança Corporativa do Brasil, especificamente no } \\
\text { setor de telecomunicações. }\end{array}$ \\
\hline $\begin{array}{c}\text { Purcinelli, L. M.; } \\
\text { Abreu, R.; Roux, A. M. } \\
\text { (2019) }\end{array}$ & 2019 & $\begin{array}{l}\text { Automation Through an ERP } \\
\text { System of the Accounting } \\
\text { and Internal Control } \\
\text { Procedures According with } \\
\text { SOX Law }\end{array}$ & $\begin{array}{l}\text { Os autores procuraram demonstrar a importância de um Sistema } \\
\text { de Planejamento de Recursos Empresariais (ERP) através da } \\
\text { relevância do processo de tomada de decisão na área de } \\
\text { compras, devido à análise de lacunas evidenciada pela aplicação } \\
\text { dos requisitos da Lei SOX. O artigo se apoia, } \\
\text { metodologicamente em uma análise teórica por meio da revisão } \\
\text { de literatura na área de contabilidade e auditoria relevantes para } \\
\text { o desempenho da empresa. A análise empírica mostra o sistema }\end{array}$ \\
\hline
\end{tabular}




\begin{tabular}{|c|c|c|c|}
\hline & & & $\begin{array}{l}\text { de controles internos implantado na área de compras. Os } \\
\text { resultados demonstraram que um Sistema ERP promove maior } \\
\text { segurança e transparência dos processos, bem como, facilita a } \\
\text { implementação de controles internos que suportam as estratégias } \\
\text { e as decisões de compra com melhor resultado financeiro e de } \\
\text { acordo com os requisitos estabelecidos pela Lei SOX. }\end{array}$ \\
\hline Wintoki, M. B. (2007) & 2007 & $\begin{array}{l}\text { Corporate boards and } \\
\text { regulation: The effect of the } \\
\text { Sarbanes-Oxley Act and the } \\
\text { exchange listing } \\
\text { requirements on firm value. }\end{array}$ & $\begin{array}{l}\text { O autor usou custos e benefícios relativos ao monitoramento } \\
\text { externo como referência, e encontra uma variação transversal } \\
\text { significativa nos efeitos de riqueza em torno do anúncio e da } \\
\text { aprovação desses regulamentos. O artigo propôs que as } \\
\text { empresas que têm altos custos de monitoramento e menos } \\
\text { benefícios do monitoramento externo se beneficiaram menos } \\
\text { com os regulamentos. }\end{array}$ \\
\hline
\end{tabular}

Fonte: Autores.

Vale destacar que, Agrawal, Johnson, Kiernan \& Leymann (2006) propuseram uma solução que incluiu: modelagem de fluxos de trabalho necessários, aplicação ativa de atividades de controle, auditoria de fluxos de trabalho reais para verificar a conformidade com controles internos e OLAP orientado por descoberta para identificar irregularidades em dados financeiros.

Dessa forma, considerou-se este trabalho como o que apresentou maior proximidade com o aqui desenvolvido, uma vez que abordou temas técnicos da área de TI como o OLAP, desenvolvido sobre o banco de dados financeiro, e não somente fatores aplicados na gestão dos processos.

\subsection{Levantamento das informações}

As informações apresentadas no trabalho foram obtidas junto a profissionais de TI, que trabalharam em uma empresa do ramo financeiro. Por motivo de sigilo com respeito às informações, o nome da empresa foi omitido.

$\mathrm{O}$ ambiente no qual essas informações foram processadas e armazenadas foi o da plataforma Mainframe. O modelo do computador Mainframe utilizado nesses processamentos foi o IBM® z990 com capacidade de processar 450 milhões de informações por segundo. Os programas tiveram seus códigos-fonte desenvolvidos na linguagem COBOL II® e manipulavam informações do Sistema de Gerenciamento de Banco de Dados IBM® DB2.

O levantamento dessas informações foi feito mediante consultas a arquivos históricos, onde estão armazenadas as informações dos processamentos das aplicações online e do processamento das rotinas batch, nos períodos definidos como Pré Lei SOX e Pós Lei SOX. O Quadro 1 mostra as datas de início e término dos períodos definidos como Pré Lei SOX e Pós Lei SOX.

Quadro 1. Períodos Pré Lei SOX e Pós Lei SOX.

\begin{tabular}{|c|c|c|c|}
\hline \multicolumn{2}{|c|}{ Pré Lei SOX } & \multicolumn{2}{c|}{ Pós Lei SOX } \\
\hline Início & Fim & Início & Fim \\
\hline Março-2006 & Junho-2006 & Outubro-2006 & Abril-2008 \\
\hline
\end{tabular}

Fonte: Autores. 


\subsubsection{Adequação dos processos operacionais de tecnologia da informação}

No levantamento das informações, a sequência dos processos de TI que foram auditados pela Lei SOX na área financeira, envolveu os seguintes processos:

- Adequação dos Programas à Lei SOX.

- Adequação dos Processos de Geração de Relatórios à Lei SOX.

- Adequação das Aplicações e Rotinas da Área Financeira à Lei SOX.

- O Impacto nos Processos de Controle Pós Lei SOX.

- O Impacto no Processamento das Rotinas batch Pós Lei SOX.

- O Impacto no Processamento das Aplicações online Pós Lei SOX.

- O Impacto na Quantidade de Informações Armazenadas Pós Lei SOX.

\section{Análise Comparativa e Discussão dos Resultados}

O início do projeto de adequação da área financeira da empresa às exigências da Lei SOX, ocorreu em novembro de 2005. Essa data foi escolhida pela diretoria da empresa, conjuntamente com os investidores, após a decisão de se dar início à comercialização das ações da empresa nas bolsas de valores norte-americanas em junho de 2006, data final do projeto.

Com as adequações às exigências da Lei SOX finalizadas e mediante as informações obtidas, foram desenvolvidas análises comparativas entre os processos envolvidos nos períodos Pré Lei SOX e Pós Lei SOX, apresentadas na sequência.

\subsection{Adequação dos programas à lei SOX}

Com a adequação às exigências da lei SOX, foram identificados programas que deviam ser alterados. Os procedimentos padrões definidos na empresa para a alteração do código-fonte de um programa classificado como Programa Não SOX, eram:

- Acessar a biblioteca de programas de produção no computador Mainframe;

- Identificar a versão do programa que sofrerá a alteração no seu código-fonte;

- Copiar a versão do programa para a área do programador responsável pela alteração;

- Alterar o código-fonte do programa em questão;

- Catalogar o programa na biblioteca de programas do ambiente de desenvolvimento;

- Testar a execução da nova versão do programa no ambiente de desenvolvimento;

- Validar os resultados dos testes junto aos usuários da área produto;

- Gerar evidências dos testes executados no ambiente de desenvolvimento;

- Solicitar o De Acordo via email, do gerente da área financeira para a catalogação da nova versão do programa na biblioteca de programas do ambiente de produção;

- Catalogar o programa na biblioteca de produção, com a nova versão.

Os procedimentos, adequados às exigências da Lei SOX, definidos para a alteração do código-fonte de um programa classificado como Programa SOX, passaram a ser:

- Solicitar autorização via email do gerente da área financeira para iniciar a alteração do programa; 
- Acessar a biblioteca de programas de produção no computador Mainframe;

- Identificar a versão do programa que sofrerá a alteração no seu código-fonte;

- Copiar a versão do programa para a área do programador responsável pela alteração;

- $\quad$ Alterar o código-fonte do programa em questão;

- Solicitar autorização via email, do gerente para catalogar o programa na biblioteca de programas do ambiente de desenvolvimento;

- Catalogar o programa na biblioteca de programas do ambiente de desenvolvimento;

- Testar a execução da nova versão do programa no ambiente de desenvolvimento;

- Validar os resultados dos testes junto aos usuários da área produto;

- Gerar evidências dos testes executados no ambiente de desenvolvimento;

- Encaminhar via email às evidências dos testes executados no ambiente de desenvolvimento ao gerente da área;

- Solicitar o De Acordo via email, do usuário com respeito aos testes executados;

- Solicitar o De Acordo via email, do gerente da área do usuário com respeito aos testes executados;

- Solicitar o De Acordo via email, do gerente da área financeira com respeito aos testes executados;

- Solicitar o De Acordo via e-mail, do superintendente da área financeira para a catalogação da nova versão do programa na biblioteca de programas do ambiente de produção;

- Catalogar o programa na biblioteca de produção, com a nova versão.

A análise revela que os procedimentos referentes à adequação do programa classificado como Programa SOX requerem autorizações registradas de níveis hierárquicos superiores. Esses novos procedimentos passaram a gerar registros das autorizações e registros de informações sobre seus processamentos: Data inicial de execução; Hora inicial de processamento; Data final de execução; Hora final do processamento; Volume de registros de informações financeiras de entrada; Volume de registros de informações financeiras de saída; Nome do analista de sistemas responsável pelo processamento; Nome do analista de produção responsável pelo turno operacional.

A análise do processo de execução de programas, após as adequações às exigências da lei SOX permite se chegar às seguintes conclusões: Os procedimentos, para que fossem feitas alterações em códigos fontes de programas, passaram a necessitar de autorizações dos gerentes (registradas via e-mail), evidenciando sua ciência e envolvimento. Os processamentos dos programas passaram a gerar informações detalhadas e rastreáveis e também com a ciência e envolvimento dos gestores.

\subsection{Adequação dos processos de geração de relatórios à lei SOX}

Foram definidos dois tipos de relatórios conforme segue:

- Relatório SOX: são os que acessam e extraem informações financeiras confidenciais. São relatórios de cenários encaminhados à superintendência e diretoria e geram planos de ações junto a grupos de clientes. Esses relatórios mostram informações sobre: Classificação do cliente; Recuperação de crédito; Redução de inadimplência; Acordos para refinanciamentos; Ações de produtos para grupos específicos.

- Relatório Não SOX: são os que acessam e extraem informações financeiras não confidenciais. São relatórios de situações específicas de clientes, focando cenários pontuais, não estratégicos. São gerados para suporte à análise da situação de clientes: Situação do cliente; Inadimplência do cliente; estatística de crédito do cliente; Previsão de 
crédito; Liberação de crédito.

Os procedimentos padrões definidos na empresa para a extração das informações do DM da área financeira para um relatório classificado como Relatório Não SOX, são: Acesso ao Data Mart (pequeno armazém de dados, que abrange uma determinada área de assunto e oferece informações mais detalhadas sobre o mercado ou departamento em questão) da área financeira; Identificação e validação de usuário e senha no sistema; Identificação como usuário Não SOX; Acesso à lista de relatórios pré-definidos ou acesso à tela de codificação de comando, para geração de novo relatório; Seleção e execução do processamento que gerará o relatório e Opção de impressão ou envio para e-mail do usuário.

Os procedimentos, adequados às exigências da Lei SOX, definidos para a extração das informações confidenciais do DM da área financeira, para um relatório classificado como Relatório SOX, são: Acesso ao Data Mart (DM) da área financeira; Identificação e validação de usuário e senha no sistema; Identificação como usuário SOX: o sistema envia um email ao gerente da área financeira comunicando o acesso ao Data Mart desse usuário e solicita sua autorização.

O gerente acessa o DM da área financeira com seu usuário e senha para conceder a autorização; Acesso à lista de relatórios pré-definidos; Seleção de relatório: o sistema atualiza a tabela de controle com o relatório selecionado pelo usuário e Execução do processamento que gerará o relatório.

Ao término da execução, o sistema atualiza a tabela de controle com as seguintes informações: Data inicial de execução; Hora inicial de processamento; Data final de execução; Hora final do processamento; Identificação do usuário SOX que solicitou o processamento do relatório; Identificação do usuário do gerente que autorizou o processamento. Ao término do processamento o sistema envia um email aos gestores comunicando o acesso ao DM.

A análise desse processo revela que os procedimentos referentes à extração de informações confidenciais, gerando um Relatório SOX, possuem processos que são registrados em uma tabela de controle, fato que torna o procedimento totalmente rastreável e, ao final do procedimento há também a comunicação aos gestores, caracterizando assim, seu envolvimento direto nesse tipo de atividade, além do gerente autorizador.

A análise do processo de extração de informações do DM, após as adequações às exigências da Lei SOX, permite se chegar às seguintes conclusões: Os procedimentos de acesso e permissão para a extração de informações passaram a depender de uma autorização do gerente para sua continuidade; As extrações de informações passaram a ser somente prédefinidas, sem a opção de codificação de comando específico para a geração do relatório; O manuseio das informações gera registros na tabela de controle permitindo sua rastreabilidade e auditoria e as extrações das informações passaram a gerar informações detalhadas e rastreáveis e também com a ciência e envolvimento dos gestores.

\subsection{Adequação das aplicações e rotinas da área financeira à lei SOX}

A área financeira possui um sistema de informação e, por meio dos processamentos, recebe as informações de outros sistemas adjuntos à área financeira da empresa. Esse volume é dividido em duas modalidades de processamento:

- Aplicações online: responsáveis por 35\% das informações financeiras, sendo estas atualizadas diretamente no banco de dados da área financeira. Os acessos são feitos, geralmente, no horário comercial estendido, ou seja, internamente na empresa esse período é definido entre 9:00 horas e 19:00 horas de segunda a sexta-feira.

- Rotinas batch: respondem por 65\% das informações atualizadas diretamente no banco de dados da área financeira. São processadas nos períodos em que as aplicações online não estão mais disponíveis para manipulação dos usuários: entre 22:00 horas e 7:00 horas de segunda a sexta-feira. 
O Quadro 2 mostra o volume de cada uma das modalidades de processamento online e batch.

Quadro 2. Modalidades de processamento.

\begin{tabular}{|c|c|c|c|}
\hline Modalidades de Processamento & online & batch & Total \\
\hline Características & 830 & 2248 & 3078 \\
\hline Quantidade de Rotinas & 27 & 73 & 100 \\
\hline Percentual (\%) & & & \\
\hline
\end{tabular}

Fonte: Autores.

Conforme mostrado no Quadro 2, das 3.078 rotinas da área financeira, 830 são aplicações online, ou seja, 27\%, os demais $73 \%$ correspondem às rotinas batch. Com o término dos processamentos batch às 7:00 horas, as informações financeiras estão atualizadas no banco de dados e são transferidas para o DM, a fim de permitir que os usuários possam desenvolver suas atividades cotidianas.

Com a adequação às exigências da Lei SOX na empresa, ambas, aplicações online e rotinas batch tiveram que ser adaptadas: 543 das 830 aplicações on line da área financeira tiveram que ser adequadas às exigências da Lei SOX, bem como 1.550 de um total de 2.248 rotinas batch sofreram adequações.

$\mathrm{O}$ processo de adequação na área financeira atingiu 2.093 rotinas, ou seja, $68 \%$ das 3.078 rotinas do sistema de informação da área financeira.

\subsection{Impacto nos processos de controle pós lei SOX}

As informações disponibilizadas no DM têm sua origem no banco de dados da área financeira e são atualizadas neste, através das aplicações online manipuladas pelos usuários e dos processamentos batch. Estes processamentos recebem informações dos arquivos intermediários e dos demais sistemas que executam suas rotinas batch.

A Figura 1 mostra o fluxo das informações, nas atualizações do banco de dados da área financeira, antes das adequações às exigências da Lei SOX. 
Figura 1: Fluxo das Informações nas atualizações do banco de dados da área financeira antes das adequações às exigências da Lei SOX.

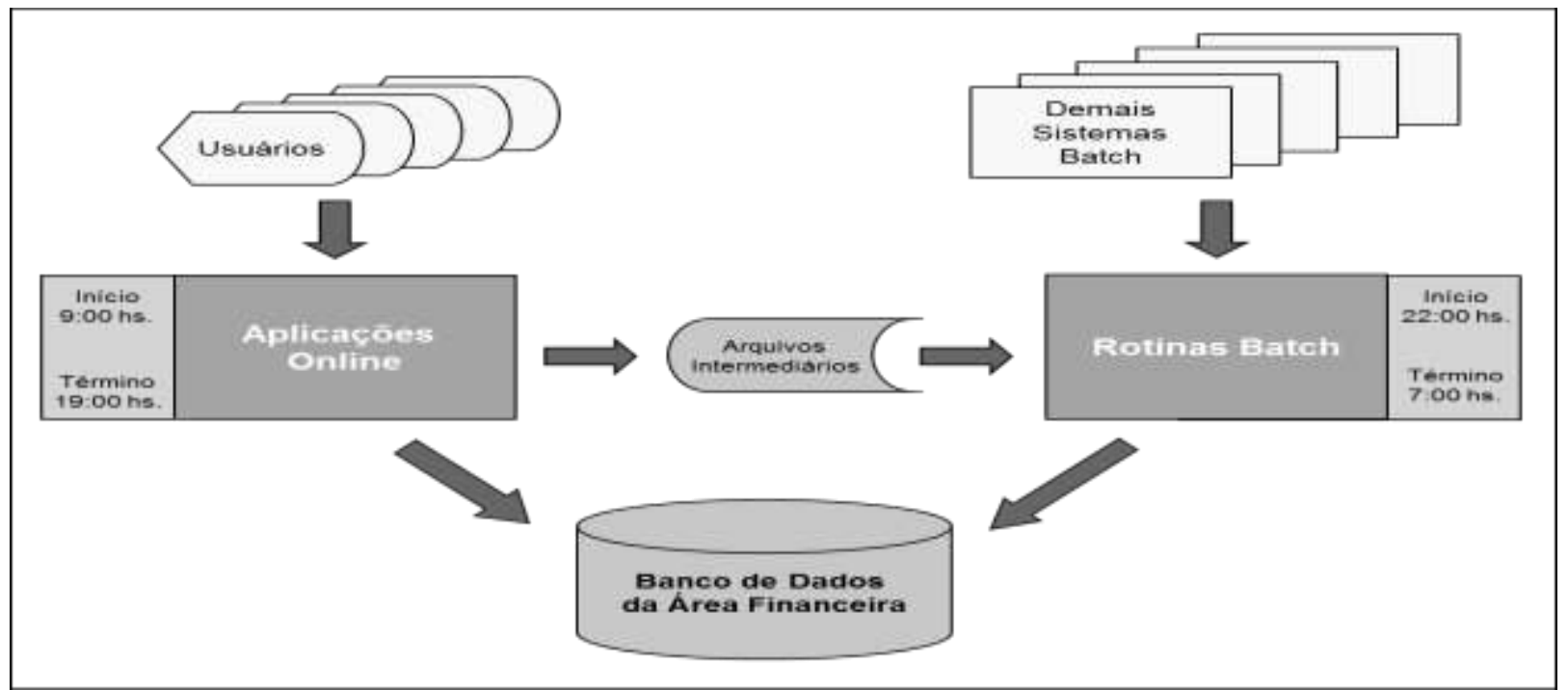

Fonte: Autores.

Conforme mostrado na Figura 1, os fluxos das informações nas atualizações do banco de dados da área financeira são manipulados pelos usuários pelas aplicações online, estas são executadas sob permissões específicas, ou seja, não são todos os usuários que conseguem alterar quaisquer informações do banco de dados da área financeira.

Em alguns casos em que essas manipulações não têm a necessidade explícita de serem executadas imediatamente, elas são gravadas cumulativamente em arquivos intermediários e, posteriormente, fornecidas como entradas dos processamentos batch.

Segundo as informações obtidas junto ao profissional de TI e especialista em finanças, foram definidas permissões aos usuários com o objetivo de se gerar um critério nos acessos às informações.

Ocorre, porém que, para atender as exigências da Lei SOX, mesmo com a definição das permissões aos usuários no acesso às informações, as manipulações das informações executadas no banco de dados da área financeira não eram registradas.

Dessa forma, não havia um histórico das atualizações executadas no banco de dados. As atividades eram desenvolvidas e somente o usuário poderia ser identificado como sendo o autor. Caso fosse necessário rastrear as atividades de um usuário específico, uma série de providências técnicas deveria ser tomada, como o acesso à área de log do sistema operacional do computador.

Os processamentos das rotinas batch, além de receberem as informações de arquivos intermediários com dados pré-processados, recebem também informações dos demais sistemas batch e atualizam o banco de dados da área financeira. As adequações geraram a implantação de novos processos de controle SOX e geraram um impacto no cotidiano dos processamentos das rotinas da área financeira.

A Figura 2 mostra o fluxo das informações, nas atualizações do banco de dados da área financeira, após as adequações às exigências da Lei SOX. 
Figura 2: Fluxo das informações nas atualizações do banco de dados da área financeira após as adequações às exigências da Lei SOX.

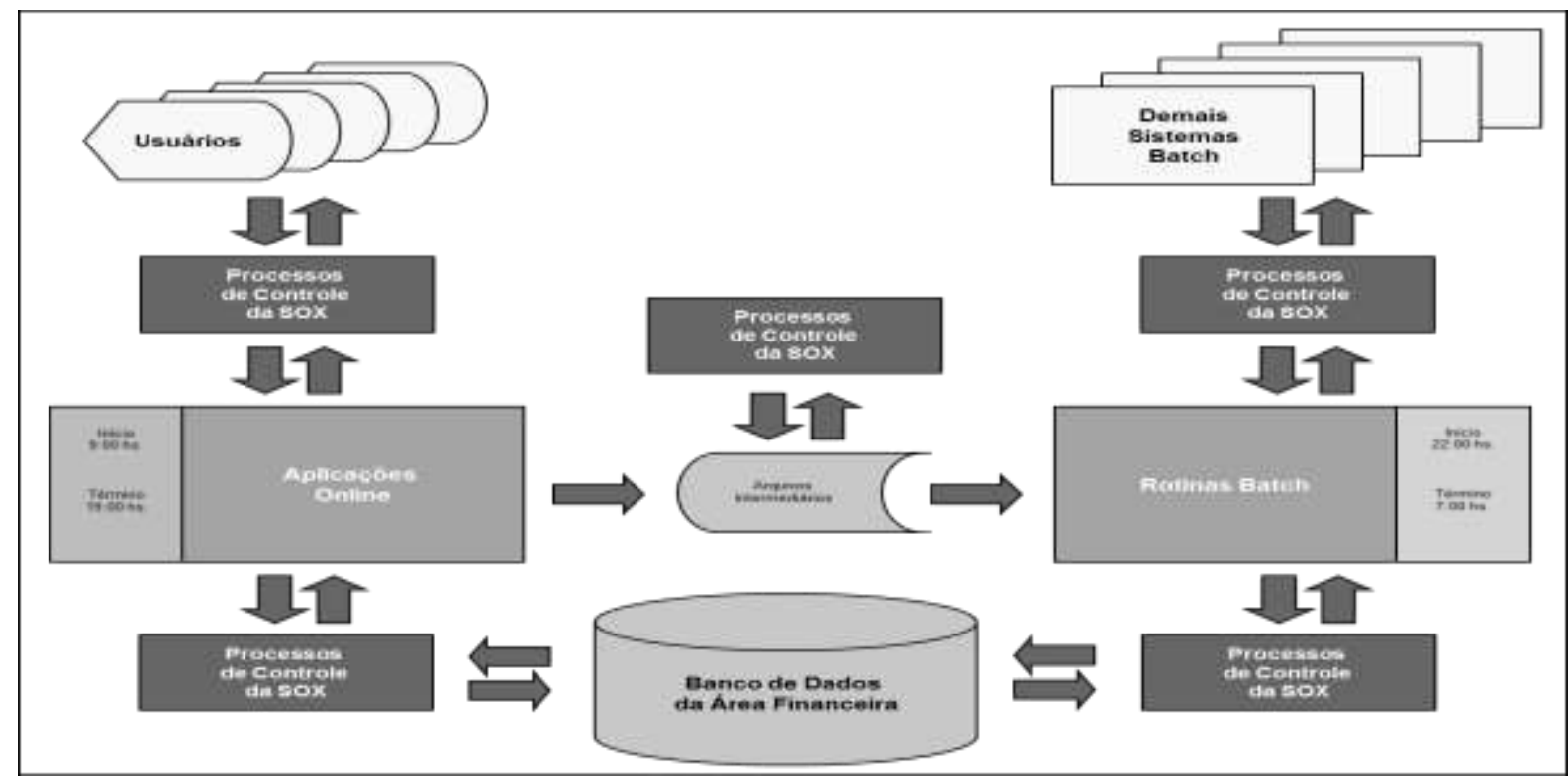

Fonte: Autores.

A Figura 2 mostra que as adequações influenciaram o fluxo das informações no sistema de informações financeiro, pois os novos controles SOX implantados passaram a fazer parte de toda a comunicação das informações desse sistema.

Os controles SOX geram registros gravados na tabela de controle, a fim de tornar os processamentos rastreáveis e auditáveis com as seguintes informações sobre as execuções: Data inicial de execução; Hora inicial de processamento; Data final de execução; Hora final do processamento; Volume de registros de informações financeiras de entrada; Volume de registros de informações financeiras de saída; Nome do analista de sistemas responsável pelo processamento; Nome do analista de produção responsável pelo turno operacional.

As análises das informações obtidas revelaram que as implantações dos controles SOX geraram um impacto aos processamentos das aplicações online e rotinas batch, pois, estas passaram a executar novas atividades nos processamentos e em função disso, o tempo de execução dos seus processamentos se estenderam.

As aplicações online passaram a ter o tempo entre a solicitação do usuário e a efetiva disponibilização da informação (tempo de resposta) maior por parte do sistema, assim como os processamentos das rotinas batch se estenderam. Ambas as modalidades passaram a ocupar um espaço em disco maior para armazenamento dos registros de controle gerados na tabela de controle.

\subsection{Impacto no processamento das rotinas batch pós lei SOX}

As rotinas batch são agendadas para processamento no período noturno e madrugada, pois recebem informações dos arquivos intermediários, gerados pelas aplicações online e pelos demais sistemas batch, pertencentes às áreas adjuntas à financeira.

Segundo as informações obtidas, três sistemas de informações: Contabilidade, Recebimento e Faturamento, enviam informações diárias ao sistema financeiro, que as processa e alimenta o banco de dados financeiro.

Esses processamentos batch, de acordo com as informações colhidas, são executados por meio de rotinas e possuem horários pré-determinados para suas execuções. A área de TI da empresa possui um mapa de processamentos onde 
constam todos os processamentos das rotinas batch de cada mês, projetadas para o ano inteiro.

Assim sendo, cotidianamente, nos horários pré-determinados entre 22:00 horas e 7:00 horas as rotinas batch são liberadas para processamento automaticamente por sistemas de controle nos computadores mainframe e os tempos de suas execuções são previstos e estimados em função o volume de informações recebidas e processadas.

\section{-Tempo Médio de Processamento das Rotinas batch Pós Lei SOX}

Foram colhidas informações semanais, desde o mês de março de 2006 (Pré Lei SOX) até junho de 2008 (Pós L ei SOX), dos tempos médios de processamentos das rotinas batch no computador Mainframe.

O Quadro 3 mostra os tempos médios de processamentos das rotinas batch de três rotinas dos sistemas: Contabilidade, Recebimento e Faturamento, no período Pré lei SOX. Os tempos médios foram calculados pela média aritmética dos tempos de processamentos das rotinas batch.

Quadro 3: Tempos médios de processamento das rotinas batch no período Pré Lei SOX.

\begin{tabular}{|c|c|c|c|c|c|c|}
\hline \multirow[b]{3}{*}{ Sistema } & \multirow{3}{*}{$\begin{array}{c}\text { Código } \\
\text { da } \\
\text { Rotina }\end{array}$} & \multicolumn{5}{|c|}{ Pré Lei SOX } \\
\hline & & \multicolumn{5}{|c|}{ Tempos médios de processamentos em minutos } \\
\hline & & $\begin{array}{c}6 / 3 / 2006 \\
a \\
10 / 3 / 2006\end{array}$ & $\begin{array}{c}24 / 4 / 2006 \\
a \\
28 / 4 / 2006\end{array}$ & $\begin{array}{c}15 / 5 / 2006 \\
a \\
19 / 5 / 2006\end{array}$ & $\begin{array}{c}5 / 6 / 2006 \\
a \\
9 / 6 / 2006\end{array}$ & $\begin{array}{c}19 / 6 / 2006 \\
a \\
23 / 6 / 2006\end{array}$ \\
\hline Contabilidade & $\mathrm{CO} 23$ & 358 & 358 & 357 & 362 & 363 \\
\hline Recebimento & RE41 & 370 & 371 & 372 & 369 & 373 \\
\hline Faturamento & FA03 & 346 & 345 & 345 & 347 & 348 \\
\hline
\end{tabular}

Fonte: Autores.

Com a implementação das adequações à Lei SOX, o tempo médio de processamento das rotinas batch, bem como da geração de informações que as alimentam sofreram impacto.

Atendendo as exigências da Lei SOX, novos processos de autorizações e registros de controle foram implantados com objetivo de tornar rastreáveis todas as execuções. A criação de tabelas e arquivos de controle, para esse registro das execuções, influenciou o tempo de processamento das rotinas batch da área financeira.

O Quadro 4 mostra os tempos médios de processamento das mesmas Rotinas batch mostradas no Quadro 3, porém, no período Pós Lei SOX. 
Research, Society and Development, v. 10, n. 1, e7710111374, 2021

(CC BY 4.0) | ISSN 2525-3409 | DOI: http://dx.doi.org/10.33448/rsd-v10i1.11374

Quadro 4: Tempos médios de processamento das rotinas batch no período Pós Lei SOX.

\begin{tabular}{|c|c|c|c|c|c|c|}
\hline \multirow{2}{*}{ Sistema } & \multirow{3}{*}{$\begin{array}{c}\text { Código } \\
\text { da }\end{array}$} & \multicolumn{6}{|c|}{ Tempos médios de processamentos em minutos } \\
\cline { 3 - 8 } & Rotina & $2 / 10 / 2006$ & $5 / 2 / 2007$ & $25 / 6 / 2007$ & $5 / 11 / 2007$ & $14 / 4 / 2008$ \\
& & $a$ & a & a & a & a \\
& & $6 / 10 / 2006$ & $9 / 2 / 2007$ & $29 / 6 / 2007$ & $9 / 11 / 2007$ & $18 / 4 / 2008$ \\
\hline Contabilidade & CO23 & 412 & 412 & 413 & 411 & 414 \\
\hline Recebimento & RE41 & 406 & 405 & 405 & 407 & 407 \\
\hline Faturamento & FA03 & 429 & 431 & 430 & 430 & 432 \\
\hline
\end{tabular}

Fonte: Autores.

$\mathrm{Na}$ análise nota-se que houve um acréscimo no tempo médio de processamento das rotinas batch comparando-se as execuções dos mesmos processamentos para ambos períodos, Pré Lei SOX e Pós Lei SOX. A Figura 3 mostra a comparação do tempo médio dos processamentos das rotinas batch nos períodos Pré Lei SOX e Pós Lei SOX.

Figura 3: Tempo Médio dos processamentos das rotinas batch.

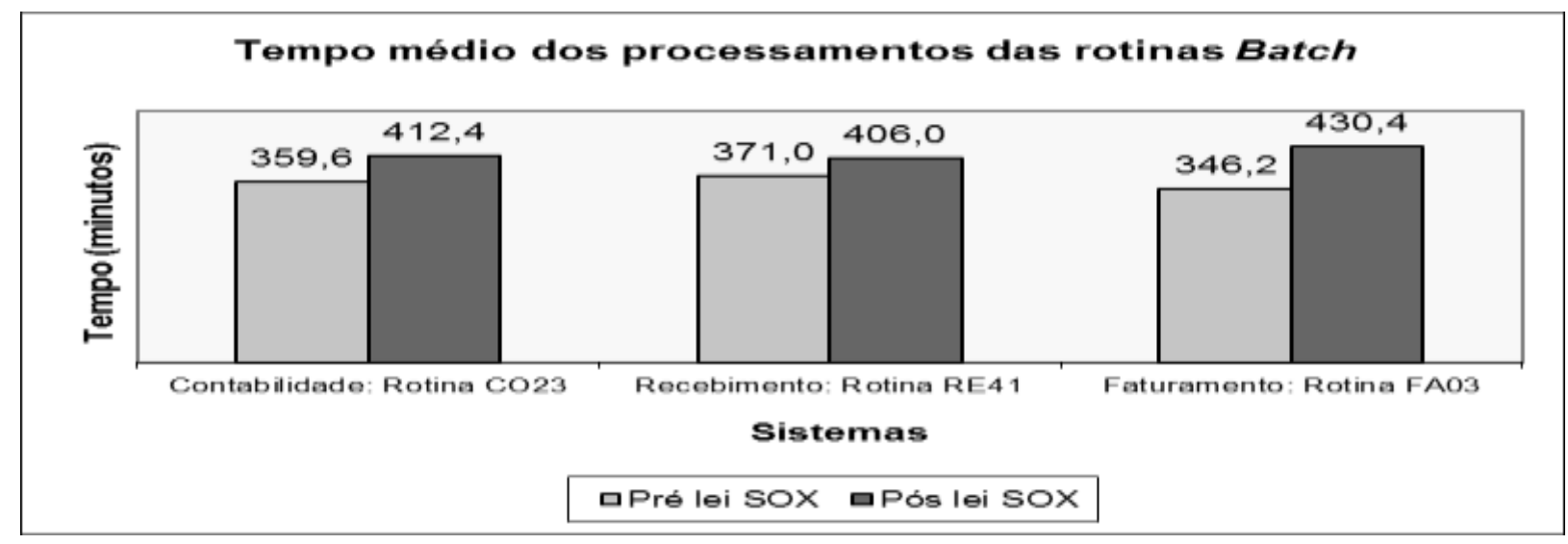

Fonte: Autores.

O Quadro 5 mostra as médias aritméticas dos tempos de processamento das rotinas batch. A média aritmética foi calculada somente sobre os tempos das execuções dos processamentos das rotinas batch mostrada nos Quadros 3 e 4 . É mostrado também no Quadro 5 o percentual de acréscimo de tempo dos processamentos das rotinas batch citadas, nos períodos Pré Lei SOX e Pós Lei SOX. 
Quadro 5: Médias aritméticas dos tempos dos processamentos das rotinas batch.

\begin{tabular}{|c|l|c|c|c|}
\hline \multirow{2}{*}{ Sistema } & \multirow{2}{*}{$\begin{array}{c}\text { Código da } \\
\text { Rotina }\end{array}$} & \multicolumn{3}{|c|}{ Médias aritméticas dos tempos dos processamentos das } \\
& & $\begin{array}{c}\text { Pré Lei SOX (tempo } \\
\text { em minutos) }\end{array}$ & $\begin{array}{c}\text { Pós Lei SOX (tempo } \\
\text { em minutos) }\end{array}$ & $\begin{array}{c}\text { Percentual } \\
(\%)\end{array}$ \\
\hline Contabilidade & CO23 & 359,6 & 412,4 & $+14,68$ \\
\hline Recebimento & RE41 & 371,0 & 406,0 & $+9,43$ \\
\hline Faturamento & FA03 & 346,2 & 430,4 & $+24,32$ \\
\hline
\end{tabular}

Fonte: Autores.

Esse acréscimo de tempo nas execuções dos processamentos das rotinas batch gerou a necessidade de serem desenvolvidas análises e reavaliações nos processos de: liberação das informações para início dos processamentos; reorganização do mapa de processamento, uma vez que as rotinas diárias passaram há levar mais tempo para serem executadas e disponibilização das informações aos usuários em horário posterior ao comumente trabalhado.

\section{-Tempo Médio de Implementação de Rotinas Batch Pós Lei SOX}

Atendendo as exigências da Lei SOX, foram desenvolvidos e implantados controles de processos nas rotinas batch e o tempo médio de implantações de rotinas batch foi impactado. O Quadro 6 mostra os tempos médios de implantações dessas rotinas batch, categorizados em três grupos: rotinas batch com menos de 20 programas; rotinas batch com o número de programas entre 20 e 50 programas e rotinas batch com mais de 50 programas.

Quadro 6: Tempos médios de implantações de rotinas Batch.

\begin{tabular}{|c|c|c|c|}
\hline \multirow{2}{*}{ Grupos de rotinas batch } & \multicolumn{2}{|c|}{ Tempos médios de implantações de rotinas batch } \\
\cline { 2 - 4 } & $\begin{array}{c}\text { PRÉ-SOX } \\
\text { (semanas) }\end{array}$ & $\begin{array}{c}\text { PÓS-SOX } \\
\text { (semanas) }\end{array}$ & Percentual (\%) \\
\hline Menos de 20 programas & 3 & 4 & $+33,33$ \\
\hline Número de programas entre 20 e 50 & 7 & 1 & $+42,85$ \\
programas & 9 & 0 & $+44,44$ \\
\hline
\end{tabular}

Fonte: Autores.

O Quadro 6 apresentou as datas de início e término dos períodos definidos em que foram colhidas as informações e analisadas as implementações de rotinas batch, nos períodos Pré Lei SOX e Pós Lei SOX.

Conforme mostrado no Quadro 6 houve um acréscimo no tempo médio das implantações de rotinas batch, gerado com as adequações às exigências da Lei SOX. Esse acréscimo de tempo gerou aumento dos custos envolvidos devido a necessidade de um número maior de profissionais envolvidos no projeto; extensão do tempo de desenvolvimento das atividades de adequação, a necessidade de se rever todos os orçamentos dedicados a cada uma das áreas com projetos em implementações de rotinas batch.

Essas revisões geraram impactos na maneira de condução dos projetos pelos gestores em função do prolongamento 
dos cronogramas. Os gestores passaram a redimensionar suas métricas de desenvolvimento para as equipes.

\subsection{Impacto no processamento das aplicações online pós lei SOX}

No manuseio das informações pelos usuários, as aplicações online são subdivididas em atividades: consulta, inclusão, alteração e exclusão. Segundo as informações colhidas, cada uma dessas atividades possui um percentual específico de acesso ao banco de dados da área financeira: Consulta: corresponde a $60 \%$ dos acessos, Alteração: corresponde a $20 \%$ dos acessos, Inclusão: corresponde a 15\% dos acessos e Exclusão corresponde a 5\% dos acessos.

Todas essas atividades foram adequadas às exigências da Lei SOX, com a implantação dos controles SOX. Estas atividades passaram a gerar registros de controle, gravados na tabela de controle, a fim de tornar as manipulações rastreáveis e auditáveis com as seguintes informações: Data inicial do acesso; Hora inicial do acesso; Data final do acesso; Hora final do acesso; Identificação do usuário que está fazendo o acesso; Nome da aplicação online acessada; Identificação do gerente que autorizou o acesso e Registro de confirmação da alteração, se realmente efetivada.

Com a implantação dos controles SOX, os usuários passaram a levar mais tempo em seus acessos e manipulações nas aplicações online, pois os sistemas tiveram seus tempos de execuções estendidos em função da gravação das informações citadas na tabela de controle, atendendo com isso as exigências da Lei SOX.

\section{- Tempo Médio de Processamento das Aplicações online Pós Lei SOX}

Com o intuito de analisar o impacto que as adequações às exigências da Lei SOX causaram às manipulações das aplicações online, foram analisadas as informações colhidas com respeito ao tempo de resposta dos sistemas online.

O Quadro 7 mostra alguns tempos médios de resposta no manuseio das aplicações online no sistema financeiro da empresa no período Pré Lei SOX. Os tempos médios correspondem aos acessos e manipulações das informações desenvolvidas pelos usuários e foram calculados pela média aritmética do montante de tempos de resposta das aplicações Online, aferidos entre segunda-feira e sexta-feira, no horário comercial estendido entre 9:00 horas e 19:00 horas.

Quadro 7: Tempos médios de resposta das aplicações online no período Pré Lei SOX.

\begin{tabular}{|c|c|c|c|c|c|}
\hline \multirow{5}{*}{$\begin{array}{c}\text { Aplicações } \\
\text { online }\end{array}$} & \multicolumn{5}{|c|}{ Pré Lei SOX } \\
\hline & \multicolumn{5}{|c|}{ Tempos médios de resposta (segundos) } \\
\hline & $6 / 3 / 2006$ & $24 / 4 / 2006$ & $15 / 5 / 2006$ & $5 / 6 / 2006$ & $19 / 6 / 2006$ \\
\hline & a & a & $\mathrm{a}$ & a & a \\
\hline & $10 / 3 / 2006$ & $28 / 4 / 2006$ & $19 / 5 / 2006$ & $9 / 6 / 2006$ & $23 / 6 / 2006$ \\
\hline Consulta & 2 & 2,2 & 1,8 & 2 & 2,2 \\
\hline Inclusão & 4 & 4,3 & 4,3 & 4,2 & 4,3 \\
\hline Alteração & 4,5 & 4,6 & 4,2 & 4,1 & 4,4 \\
\hline Exclusão & 3 & 3,2 & 3 & 3,1 & 3,1 \\
\hline
\end{tabular}

Fonte: Autores.

O Quadro 8 mostra alguns tempos médios de resposta no manuseio das aplicações online no sistema financeiro da empresa no período Pós Lei SOX. 
Research, Society and Development, v. 10, n. 1, e7710111374, 2021

(CC BY 4.0) | ISSN 2525-3409 | DOI: http://dx.doi.org/10.33448/rsd-v10i1.11374

Quadro 8: Tempos médios de resposta das aplicações online no período Pós Lei SOX.

\begin{tabular}{|c|c|c|c|c|c|}
\hline \multirow{2}{*}{$\begin{array}{c}\text { Aplicações } \\
\text { online }\end{array}$} & \multicolumn{5}{|c|}{ Pós Lei SOX } \\
\cline { 2 - 6 } & $2 / 10 / 2006$ & $5 / 2 / 2007$ & $25 / 6 / 2007$ & $5 / 11 / 2007$ & $14 / 4 / 2008$ \\
& $\mathrm{a}$ & $\mathrm{a}$ & $\mathrm{a}$ & $\mathrm{a}$ & $\mathrm{a}$ \\
& $6 / 10 / 2006$ & $9 / 2 / 2007$ & $29 / 6 / 2007$ & $9 / 11 / 2007$ & $18 / 4 / 2008$ \\
\hline Consulta & 2 & 2 & 2 & 2 & 2 \\
\hline Inclusão & 5 & 5 & 5 & 5 & 5 \\
\hline Alteração & 5 & 5 & 5 & 5 & 5 \\
\hline Exclusão & 3 & 3 & 3 & 3 & 3 \\
\hline
\end{tabular}

Fonte: Autores.

$\mathrm{Na}$ análise, nota-se que houve um acréscimo no tempo médio de resposta no manuseio das aplicações online, comparando-se as execuções das atividades de consulta, inclusão, alteração e exclusão em ambos os períodos, Pré Lei SOX e Pós Lei SOX.

O Quadro 9 mostra as médias aritméticas dos tempos de resposta das aplicações online. A média aritmética foi calculada somente sobre os tempos de respostas referentes aos manuseios das aplicações online mostradas nos Quadros 7 e 8. É mostrado também no Quadro 9 o percentual de acréscimo nos tempos de resposta dos manuseios das aplicações online citadas, nos períodos Pré Lei SOX e Pós Lei SOX.

Quadro 9: Médias aritméticas dos tempos de resposta das aplicações online.

\begin{tabular}{|c|c|c|c|}
\hline \multirow{2}{*}{ Aplicações online } & \multicolumn{3}{|c|}{ Médias aritméticas dos tempos de reposta das aplicações online } \\
& \multirow{2}{*}{$\begin{array}{c}\text { Pré Lei SOX (tempo } \\
\text { em segundos) }\end{array}$} & $\begin{array}{c}\text { Pós Lei SOX (tempo } \\
\text { em segundos) }\end{array}$ & Percentual (\%) \\
\hline Consulta & 2,0 & 2,4 & + \\
\hline Inclusão & 4,2 & 5,4 & + \\
\hline Alteração & 4,3 & 5, & + \\
\hline Exclusão & 3,0 & 3,7 & + \\
\hline
\end{tabular}

Fonte: Autores.

Conforme mostrado no Quadro 9 a atividade de Consulta passou a ter seus tempos de respostas, em média, acrescidos de 21,57\%. Muitas Consultas foram adequadas para serem desenvolvidas somente após a liberação de acesso do gerente responsável, atendendo assim a exigência da Lei SOX, com respeito à responsabilidade gerencial envolvida nos processos.

A atividade de Alteração teve o maior impacto em seus tempos de resposta, quando comparada às demais. Esse tempo sofreu um aumento de 33,03\%. Todas as Alterações foram adequadas para serem desenvolvidas somente após a liberação de acesso do gerente responsável. 
A atividade de Inclusão teve seu tempo também impactado com o acréscimo de 28,44\%. Muitas Inclusões foram adaptadas para serem desenvolvidas somente após a liberação de acesso do gerente responsável. A atividade de Exclusão foi a que obteve o menor impacto em seus tempos de respostas, 20,78\%. Todas as Exclusões foram adaptadas para serem desenvolvidas somente após a liberação de acesso do gerente responsável.

O aumento dos tempos de resposta das aplicações online no período Pós Lei SOX, foi justificado pela implantação dos processos de controle SOX nos processamentos e, consequentemente, as atividades de manipulação de informações nas aplicações online tiveram um acréscimo considerável em seus tempos de respostas fazendo com que os usuários passassem a levar mais tempo em sua manipulação.

Muitas aplicações online que antes eram manuseadas somente pelos usuários, passaram a ter uma escala hierárquica de autorização para os acessos, validada por Usuário e Senha, e ainda, foi determinada a necessidade de obter uma autorização do gerente responsável pra a liberação dos acessos.

Os processos foram impactados, pois a dependência de se desenvolver a atividade dependia também do envolvimento do gerente no processo. Além desse fator processual, as aplicações online passaram a registrar todos os passos dos usuários no sistema.

\section{-Tempo Médio de Implementação das Aplicações online Pós Lei SOX}

A adequação às exigências da Lei SOX impactou o tempo de implantação das aplicações online dos sistemas de informações. Face às adequações sofridas pelas aplicações online, os cronogramas tiveram que ser adaptados para prever a geração de todos os registros de controles exigidos pela Lei SOX.

Foram levantadas informações inerentes às implantações das aplicações online, porém categorizando-as em três grupos de sistemas de informações, divididos pelo volume de programas e aplicações online envolvidos: Menor que 100; Entre 100 e 300 e Maior que 300. O Quadro 10 mostra os tempos médios de implantações das aplicações online, categorizadas nos três grupos.

Quadro 10: Tempos médios de implantações das aplicações online.

\begin{tabular}{|c|c|c|c|}
\hline \multirow{2}{*}{ Categoria } & \multicolumn{3}{|c|}{ Tempos médios de implantações das aplicações online } \\
\cline { 2 - 4 } & $\begin{array}{c}\text { Pré Lei SOX } \\
\text { (semanas) }\end{array}$ & $\begin{array}{c}\text { Pós Lei SOX } \\
\text { (semanas) }\end{array}$ & Percentual (\%) \\
\hline $\begin{array}{c}\text { Menos de 100 programas e } \\
\text { aplicações online }\end{array}$ & 16 & 20 & $+25,00$ \\
\hline $\begin{array}{c}\text { Número de programas e aplicações } \\
\text { online entre 100 e 300 }\end{array}$ & 48 & 61 & $+27,08$ \\
\hline $\begin{array}{c}\text { Mais de 300 programas e } \\
\text { aplicações online }\end{array}$ & 72 & 93 & $+29,17$ \\
\hline
\end{tabular}

Fonte: Autores.

Assim como nas adequações das rotinas batch, o aumento de tempo nas implantações gerou um aumento nos custos envolvidos no desenvolvimento dos projetos. $\mathrm{O}$ aumento gerou a necessidade de se rever todos os orçamentos dedicados a cada uma das áreas com projetos em implantações, adequando-os à nova realidade sob as exigências da Lei SOX. 


\subsection{Impacto na quantidade de informações armazenadas pós lei SOX}

Com a geração de processos de controle SOX e o consequente registro das atividades na tabela de controle tornando as atividades rastreáveis e auditáveis o volume de informações armazenadas nos sistemas de informações da área financeira aumentou significativamente.

Os sistemas são compostos por arquivos gravados nos computadores e possuem um tamanho específico. Com as adequações às exigências da Lei SOX atendidas, os processamentos passaram a gravar informações de controle e essas gravações aumentaram o tamanho ocupado anteriormente pelos arquivos.

Esse fato que gerou a necessidade de serem feitas expansões nas áreas de armazenamento de informações e, com isso, foram necessárias aquisições de mais baterias discos. O Quadro 11 mostra os percentuais de utilização no armazenamento de informações em disco (ocupação de espaço físico) dos três sistemas de informações, nos períodos Pré Lei SOX e Pós Lei SOX.

Quadro 11: Percentuais de utilização no armazenamento de informações em disco.

\begin{tabular}{|c|c|c|c|}
\hline \multirow{2}{*}{ Sistema } & \multicolumn{3}{|c|}{ Percentual de utilização no armazenamento de informações em } \\
& \multicolumn{3}{|c|}{ disco } \\
\cline { 2 - 4 } & Pré Lei SOX (\%) & Pós Lei SOX (\%) & Percentual (\%) \\
\hline Contabilidade & 83 & 91 & $+9,63$ \\
\hline Recebimento & 70 & 88 & $+25,71$ \\
\hline Faturamento & 89 & 95 & $+6,74$ \\
\hline
\end{tabular}

Fonte: Autores.

Com as aquisições de novas baterias de discos para armazenamento das informações dos sistemas, as áreas de armazenamento foram expandidas e, atualmente, os três sistemas dispõem de maiores espaços e disco para serem expandidos com as informações, constantemente gravadas.

O volume de informações gravadas em disco não era considerado como um dos principais impactos aos processos, até a efetiva constatação do percentual de crescimento que as adequações às exigências da Lei SOX causaram. Os custos gerados pelas aquisições das baterias de discos não estavam previstos no orçamento da empresa para o projeto de adequação à Lei SOX e foi mais um impacto gerado.

\section{Considerações Finais}

As determinações da Lei SOX exigiram registros, controles e autorizações para a manipulação de quaisquer processos financeiros e da área de Tecnologia da Informação (TI), onde constassem informações que, de alguma maneira, poderiam afetar os resultados financeiros da empresa.

Com as novas regras determinadas, o resultado final de cada um desses processos, sofreu um impacto com respeito à sua operacionalidade, tempo de execução e espaço para armazenamento das informações.

$\mathrm{O}$ trabalho revelou que a necessidade de adequação dos processos operacionais de Tecnologia da Informação na área financeira da empresa alterou: O processo de adequação de programas; O processo de geração dos relatórios; As aplicações e rotinas da área financeira; Os processos de controle Pós Lei SOX; O processamento das rotinas batch Pós Lei SOX; O tempo médio de processamento das rotinas batch Pós Lei SOX; O tempo médio de implementação de rotinas batch Pós Lei SOX; O 
processamento das aplicações online Pós Lei SOX; O tempo médio de processamento das aplicações online Pós Lei SOX; O tempo médio de implementação das aplicações online Pós Lei SOX e a Quantidade de informações armazenadas Pós Lei SOX;

As regras, políticas e procedimentos tiveram que ser revisados e rescritos, foram criadas novas regras e adaptações foram necessárias às já existentes, treinamentos foram aplicados, consequentemente, essas atividades fizeram com que os orçamentos destinados à área financeira tivessem que ser revisados.

$\mathrm{Na}$ empresa analisada, vários fatores que num primeiro momento não aparentavam serem críticos, requereram uma maior atenção, assim sendo, este trabalho conclui que o impacto nos processos de TI com a adequação às exigências da Lei SOX, atingiu proporções e características técnicas anteriormente sem precedentes.

O levantamento bibliográfico realizado mostrou, que apesar de importante são poucas as obras que apresentam o impacto da Lei SOX nos processos operacionais de TI. Boa parte das obras estão relacionadas aos estudos dos impactos gerenciais, o que revela a importância deste trabalho.

No âmbito acadêmico, este trabalho contribuiu com a literatura acadêmica acerca da temática da aplicação da Lei SOX em processos operacionais de TI. Espera-se que este estudo motive o aumento da pesquisa e discussão no meio acadêmico acerca de tema tão importante.

A abordagem do artigo evidencia que a empresa que opta pela adequação à Lei SOX estará elevando seu nível de segurança, porém, para tal, precisa avaliar sua capacidade de processamento e monitoramento das execuções na área de produção de TI. Eventualmente, poderá precisar investir em novos procedimentos de monitoramento e também em hardwares com maior capacidade. Espera-se que este trabalho contribua de tal forma, que as empresas possam adotá-lo como um roteiro quando implementarem a Lei SOX aos processos operacionais.

O presente trabalho evidenciou a preocupação e a necessidade das empresas sobre a transparência de seus processos e informações financeiras, buscando e se adequando às exigências legais e, absorvendo os impactos gerados por essa iniciativa. Essa postura gera uma maior confiança para seus clientes, investidores e parceiros

Sugerimos a continuidade do trabalho nos tópicos: análise do impacto da adequação dos processos operacionais de TI levantados neste trabalho na área financeira em outras empresas; análise de outros processos operacionais de TI adequados às exigências da Lei SOX; análise da comercialização das ações da empresa no mercado norte-americano após as adequações às exigências da Lei SOX e análise do comportamento dos clientes da empresa após as adequações às exigências da Lei SOX.

$\mathrm{O}$ estudo foi desenvolvido e limitado a uma empresa do ramo financeiro, o que impossibilitou a comparação com outros cenários. Destaca-se, que por motivo de sigilo houve dificuldade em encontrar outras empresas dispostas a fornecerem suas informações dos processos operacionais.

Assim, este trabalho não tem a pretensão de esgotar o assunto, pelo contrário, buscou-se contribuir para futuras novas decisões corporativas com respeito às adequações e exigências da Lei SOX.

\section{Referências}

Arrivabene, A., Sassi, R. J., \& Romero, M. (2011). Corporate sustainability with security to investors: Analyses of Business Intelligence governance following the requirements of Sarbanes-Oxley Law. Proceedings of the 3rd International Conference On Communication Software And Networks (ICCSN), pp. 224- 228. 10.1109/ICCSN.2011.6013580.

Andrade, A., \& Rossetti, J. P. (2004). Governança Corporativa: fundamentos, desenvolvimento e tendências. Atlas.

Agrawal, R., Johnson, C., Kiernan, J., \& Leymann, F. (2006). Taming Compliance with Sarbanes-Oxley Internal Controls Using Database Technology. Proceedings of the 22nd International Conference On Data Engineering (ICDE '06), pp. 92. 10.1109/ICDE.2006.155.

Badele, C. S., \& Fundeanu, D. (2014). Policy's Beneficiaries of Corporate Governance and Diversification Strategy. Procedia - Social and Behavioral Sciences, 124(20), pp. 468-477. DOI: 10.1016/j.sbspro.2014.02.509. 
Research, Society and Development, v. 10, n. 1, e7710111374, 2021 (CC BY 4.0) | ISSN 2525-3409 | DOI: http://dx.doi.org/10.33448/rsd-v10i1.11374

Bequai, A. (2003). Safeguards for IT Managers and Staff under the Sarbanes Oxley Act. Computers \& Security, $22(2), 124-127$.

Borgerth, V. M. C. (2007). SOX: Entendendo a Lei Sarbanes-Oxley. Thomson.

Broni, G., \& Velentzas, J. (2012). Corporate Governance, Control and Individualism as a Definition of Business Success. The Idea of a "Post - Heroic" Leadership. Procedia Economics and Finance, 1, pp. 61-70. 10.1016/S2212-5671(12)00009-3.

Chan, S. (2004). Sarbanes Oxley: The IT Dimension. The Internal Auditor, 61(1), 31 - 33.

Crespí-Cladera, R., \& Pascual-Fuster, B. (2014). Does the independence of independent directors matter? Journal of Corporate Finance, 28, 116-134. http://dx.doi.org/10.1016/j.jcorpfin.2013.12.009.

Claessens, S., \& Yurtoglu, B. B. (2013). Corporate governance in emerging markets: A survey. Emerging Markets Review, 15, 1-33. http://dx.doi.org/10.1016/j.ememar.2012.03.002.

Defond, M. L., \& Francis, J. R. (2005). Audit research after Sarbanes-Oxley. Auditing: A Journal of Practice \& Theory, 24,. 5-30.

Gelatti, C. B., Meneghetti, D., \& Silva, T. M. (2010). Análise da adequação das empresas brasileiras à Lei Sarbanes-Oxley. Revista Brasileira de Contabilidade, 186, pp. 69-84.

Gil, A. C. (2002). Como elaborar projetos de pesquisa. Atlas.

Hinde, S. (2004). Crime and punishment: corporate governance. Computer Fraud \& Security, 6, 4-7. http://dx.doi.org/10.1016/S1361-3723(04)00074-0.

IBGC. (2020). Instituto Brasileiro de Governança Corporativa. O que é governança corporativa. Conhecimento. Recuperado. http://www.ibgc.org.br.

ISO/IEC JTC 1/SC 40 (2015). Information technology - Governance of IT for the organization. Technical Report \#ISO/IEC 38500:2015.

Jain, S., Jain, P., \& Rezaee, Z. (2010). Stock market reactions to regulatory investigations: Evidence from options backdating. Research in Accounting Regulation, 22(1), 52-57. http://dx.doi.org/10.1016/j.racreg.2009.11.004.

Juiz C.; Palacios R. C. (2020). IEEE/ACM Extending Software Development Governance to meet IT Governance. Seoul, Republic of Korea, 2020.05.23. doi.org/10.1145/3387940.3392211.

Juiz, C. and Toomey, M. (2015). To Govern IT, or Not to Govern IT? Commun. ACM. 58, 2, 58-64. https://doi.org/10.1145/2656385.

Kaarst-Brown, M. L., \& Kelly, S. (2005). IT Governance and Sarbanes Oxley: The Latest Sales Pitch or Real Challenges for the IT Function? Proceedings of the Ieee 38th Hawaii International Conference On System Sciences, 236-246. DOI: 10.1109/HICSS.2005.361.

Karpoff, J. M. (2019). The future of financial fraud. Journal of Corporate Finance. https://doi.org/10.1016/j.jcorpfin.2020.101694.

Kim, E. H., \& Lu, Y. (2013). Corporate governance reforms around the world and cross-border acquisitions. Journal of Corporate Finance, 22 , $236-253$. http://dx.doi.org/10.1016/j.jcorpfin.2013.05.005.

Labadessa, E., Rosini, A. M., Palmisano, A., Conceição, M. M. Good hospital governance: planned adjustments for results in improving public care for patients. Research, Society and Development, [S. l.], 9(2), e06921587, 2020. 10.33448/rsd-v9i2.1587. https://rsdjournal.org/index.php/rsd/article/view/1587.

Leveson, N. (2011). Engineering a safer world: Systems thinking applied to safety. MITpress.

Li, W., Chen, C. C., \& French, J. J. (2012). The relationship between liquidity, corporate governance, and firm valuation: Evidence from Russia. Emerging Markets Review, 13(4), 465-477. http://dx.doi.org/10.1016/j.ememar.2012.07.004.

Lo, D. (2012). OHS Stewardship - Integration of OHS in Corporate Governance. Procedia Engineering, 45, 174-179. http://dx.doi.org/10.1016/j.proeng.2012.08.139.

Lunardi, G. L., Becker, J. L., \& Maçada, A. C. G. (2012). Um estudo empírico do impacto da governança de TI no desempenho organizacional. Produção, 22(3), 612-624. http://dx.doi.org/10.1590/S0103-65132012005000003.

Luo, Y. (2005). How does globalization affect corporate governance and accountability? A perspective from MNEs. Journal of International Management, 11(1), 19-41, http://dx.doi.org/10.1016/j.intman.2004.11.003.

Lynch A. H., Veland S. (2018). Urgency in the Anthropocene. MITPress.

Menezes, A. M. (2018). A Influência da Lei Sarbanes-Oxley (SOX) nas Normas e Regras Nacionais da Governança Corporativa no Setor de Telecomunicações do Brasil. 2018. 128. Dissertação - Universidade Federal do Paraná, Curitiba, 2018.

Paré, G., Guillemette, M. G. and Raymond, L. (2019). IT centrality, IT management model, and contribution of the IT function to organizational performance: A study in Canadian hospitals. Information \& Management. 103198. https://doi.org/10.1016/j.im.2019.103198.

Parkinson, J., \& Bloom S. (2003). Surviving Sarbanes Oxley. Optimize, 73, 31-42.

Posthumusa, S., \& Solms, R. Von. (2005). IT oversight: an important function of corporate governance. Computer Fraud \& Security, 2005(6), 11-17. http://dx.doi.org/10.1016/S1361-3723(05)70222-0. 
Research, Society and Development, v. 10, n. 1, e7710111374, 2021 (CC BY 4.0) | ISSN 2525-3409 | DOI: http://dx.doi.org/10.33448/rsd-v10i1.11374

Purcinelli, L. M., Abreu, R., Roux, A. M. (2019). Automation Through an ERP System of the Accounting and Internal Control Procedures According with SOX Law. IEEE 2019. 14th Iberian Conference on Information Systems and Technologies (CISTI), 2019.07.15, DOI: 10.23919/CISTI.2019.8760666.

Rezaee, Z. (2004). Corporate Governance Role in Financial Reporting. Research in Accounting Regulation, 17, 107-149, http://dx.doi.org/10.1016/S10520457(04)17006-9.

Schmitt, A., Raisch, S., \& Volberda, H. W. (2016). Strategic renewal: Past research, theoretical tensions and future challenges. International Journal of Management Reviews, 00, 1-18.

Soh D. S. B., Martinov N. B. (2011). The internal audit function: Perceptions of internal audit roles, effectiveness and evaluation. Managerial Auditing Journal, 26,7(2011),605-622.

Solms, B. Von. (2006). Information Security - The Fourth Wave. Computers \& Security, 25(3), 165-168. 10.1016/j.cose.2006.03.004.

Souza, L. O. de; Pedreiro, I. L. D.; Barbosa, A. L. M. A.; Castro, W. A. de. (2019). The influence of Corporate Governance on the profitability of Financial Institutions. Research, Society and Development, 8(8), e09881179,2019.10.33448/rsd-v8i8.1179. https://rsdjournal.org/index. php/rsd/article/view/1179.

Swartz, N. (2003). The Cost of Sarbanes Oxley. Information Management Journal, 37, 8 - 26.

Sievinen, H. M., Ik“aheimonen, T., \& Pihkala, T. (2020). Strategic renewal in a later- generation family-owned company. Long Range Planning, 53(2), 1-19.

Tan, Z. (2014). The construction of calculative expertise: The integration of corporate governance into investment analyses by sell-side financial analysts. Accounting, Organizations and Society, 39(5), 362-384, http://dx.doi.org/10.1016/j.aos.2014.05.003.

Tariq, Y. B., \& Abbas, Z. (2013). Compliance and multidimensional firm performance: Evaluating the efficacy of rule-based code of corporate governance. Economic Modelling, 35, 565-575, http://dx.doi.org/10.1016/j.econmod.2013.08.015.

Tham D. K., Madni M. A. (2014). IEEE SOX compliance with OEE, enterprise modeling and temporal-ABC. Waikoloa, HI, USA, 2014.10.27. 10.1109/WAC.2014.6935737.

Todeva, E. (2005). Governance, control and coordination in network context: the cases of Japanese Keiretsu and Sogo Shosha. Journal of International Management, 11(1), 87-109. http://dx.doi.org/10.1016/j.intman.2004.11.008.

Turel, O., Liu, P. \& Bart, C. (2019). Board-Level IT Governance. IT Professional. 21, 2, 58-65. https://doi.org/10.1109/MITP.2019.2892937.

Weill, P., \& Ross, J. W. (2004). IT Governance: How Top Performers Manage IT Decision Rights for Superior Results. Harward Business School Press.

Windsor, D. (2009). Tightening corporate governance. Journal of International Management, 15(3), 306-316. http://dx.doi.org/10.1016/j.intman.2009.02.003.

Wintoki, M. B. (2007). Corporate boards and regulation: The effect of the Sarbanes-Oxley Act and the exchange listing requirements on firm value. Journal of Corporate Finance, 139(2-3), 229-250. http://dx.doi.org/10.1016/j.jcorpfin.2007.03.001.

Zalewska, A. (2014). Challenges of corporate governance: Twenty years after Cadbury, ten years after Sarbanes-Oxley. Journal of Empirical Finance, 27, 1-9, http://dx.doi.org/10.1016/j.jempfin.2013.12.004. 